Rathbone, CJ. and Moulin, CJA. (2016) 'Switch costs in the self-memory system', Quarterly Journal of Experimental Psychology, 70 (6). pp. 1063-1073.

DOI: https://doi.org/10.1080/17470218.2015.1127398

This document is the authors' Accepted Manuscript.

License: https://creativecommons.org/licenses/by-nc-nd/4.0

Available from RADAR: https://radar.brookes.ac.uk/radar/items/f91df2df-c500-4e69-b48e-6e498e811455/1/

Copyright ( $\subseteq$ and Moral Rights are retained by the author(s) and/ or other copyright owners unless otherwise waved in a license stated or linked to above. A copy can be downloaded for personal non-commercial research or study, without prior permission or charge. This item cannot be reproduced or quoted extensively from without first obtaining permission in writing from the copyright holder(s). The content must not be changed in any way or sold commercially in any format or medium without the formal permission of the copyright holders. 
Switch costs in the self-memory system

Clare J. Rathbone ${ }^{1} \&$ Chris J.A. Moulin ${ }^{2}$

1Department of Psychology, Oxford Brookes University, Oxford, UK

${ }^{2}$ LPNC, CNRS UMR 5015, Université Piere Mendès France, Grenoble, France

RUNNING HEAD: SWITCH COSTS IN THE SELF-MEMORY SYSTEM

Corresponding author:

Dr Clare Rathbone

crathbone@brookes.ac.uk

Department of Psychology

Oxford Brookes University

Oxford, OX3 OBP, UK

Tel: 00441865483772

Word Count: 5,944

Acknowledgement: 


\title{
SWITCH COSTS IN THE SELF-MEMORY SYSTEM
}

Clare Rathbone was supported by the Economic and Social Research Council (ES/K000918/1). This research was conducted at the University of Leeds.

\begin{abstract}
Two studies on undergraduates examined the idea that the working self operates as an executive structure to constrain and co-ordinate the generation of autobiographical memories. A switching task was used, in which participants completed an autobiographical memory fluency task, either using alternating self-image cues, or the same cue repeatedly. In two experiments, there was a clear switch cost, whereby participants took longer to generate autobiographical memories when alternating between two different self-images. In the second experiment, there was also a similar cost associated with generating names and places from two separate domains, home and university. Taken together, these experiments support the idea that autobiographical memories and personal semantics are organized into a hierarchical structure, which can be probed using executive function-like tasks. In particular, the task switch cost points to retrieval systems being geared up to retrieving memories according to the current goals of the self. In terms of autobiographical retrieval, the self can thus be thought of as a mental structure which is subject to dynamic patterns of excitation and interference.

Keywords: Autobiographical memory; Self; Identity; Self-Memory System; Episodic memory; Task switching
\end{abstract}




\section{SWITCH COSTS IN THE SELF-MEMORY SYSTEM}

Switch costs in the self-memory system

Autobiographical memories allow us to make sense of the past and plan for the future. By definition, they are a highly self-relevant form of memory, encompassing the specific episodic events and factual semantic details that make up our lives. When we try to recall how we felt when finishing final school exams, a friend's name, or our first address, we engage our autobiographical memory. However, in spite of the clear self-relevance of these memories, the relationship between autobiographical memory and the self is complex and difficult to test experimentally. In this paper we use a task switching paradigm to elucidate the link between the self and autobiographical memory. In particular, we are interested in how the self may act to exert executive control on autobiographical memory retrieval.

The relationship between the self and autobiographical memory has been conceptualized as a bidirectional and goal-driven Self-Memory System (SMS, Conway \& Pleydell-Pearce, 2000; Conway, 2005). Within the SMS, autobiographical memories are thought to form the database for the 'working self', which is in turn envisaged as a set of active goals and self-images (Conway, 2005). Conway suggests that this aspect of the SMS is executive in its nature: "the goal hierarchy of the working self operates as a set of control processes that determine encoding, accessibility of knowledge in long-term memory, and the construction of memories" (Conway, 2005; p.597).

The SMS is proposed to be bi-directional, in that the working self governs what is retrieved from autobiographical memory whilst information stored in autobiographical memory constrains the working self. The SMS predicts raised accessibility for memories that are most relevant to the active goals of the working self, in contrast to memories that are less relevant. In turn, the accessibility of particular self-images (i.e. self-descriptions, such as being faithful, lonely, or an athlete) would be raised in the context of retrieval of a congruent autobiographical memory (recalling memories of 


\section{SWITCH COSTS IN THE SELF-MEMORY SYSTEM}

competing in sporting events would activate the goals and self-images associated with being an athlete, for example).

The idea that the self organises autobiographical retrieval extends back to work by Markus (1977; Markus \& Kunda, 1986), who also suggested that the 'working self-concept' has executive properties, summarising and organising records of behaviour. Since then, a number of studies have suggested that the self plays an important role in the construction of past events, by biasing retrieval towards events that are most congruent with current self-images (e.g. Barclay and Subramaniam, 1987; Greenwald, 1980). For example, Stopa and Jenkins (2007) manipulated whether participants held positive or negative self-images in mind, and then investigated speed of subsequent autobiographical memory retrieval. There was a congruency effect, with positive and negative selfimages facilitating retrieval of valence-congruent autobiographical memories, and inhibiting retrieval of incongruent autobiographical memories. Wang (2008) investigated the effects of self-primes on autobiographical memory retrieval by asking Asian American participants to focus on cultural selfprimes (e.g. completing the statement 'As an American/Asian I am...') prior to autobiographical memory generation. Results showed that those primed with the American self gave memories that were less socially-orientated and more self-focused (autonomous) than those who were primed with an Asian self-image. A control group, who were primed with descriptions of nature (e.g. 'The tree is...'), generated memories with ratings for autonomy that fell in between the two cultural prime conditions. Wang and Ross (2005) carried out a similar study priming the private and collective self prior to autobiographical memory generation, and found that memory content was congruent with the aspect of self that was primed. Further supporting the idea that the self plays an executive role in autobiographical retrieval, in previous work we found that people's most salient self-images were associated with more accessible sets of self-image cued autobiographical memories (Rathbone \& Moulin, 2014). 


\section{SWITCH COSTS IN THE SELF-MEMORY SYSTEM}

These studies suggest that when a particular self-image is activated, cognitive resources will process and retrieve autobiographical memories that are consistent with that aspect of the self (e.g. Conway \& Pleydell-Pearce, 2000; Wang, 2008). In line with the bi-directional SMS, these effects have also been shown in the opposite direction. In a recent study, Cili and Stopa (2015) found that participants reported higher state self-esteem following retrieval of a positive, compared to a negative, selfdefining memory. In a second experiment, Cili and Stopa examined the content of self-images generated by participants after recalling positive and negative self-defining memories. They found marginally significant trends, suggesting that the valence of a retrieved memory has an impact on the types of self-images that come to mind post-recall.

In contrast to the research reviewed above, which suggests clear links between self and autobiographical memory, other studies present a more complex picture. Klein and colleagues have conducted a series of priming studies, investigating the role of self-knowledge in autobiographical memory retrieval (e.g. Klein \& Loftus, 1993). These studies typically involve three tasks: define a trait word (e.g. cheerful); decide whether a trait word describes oneself; recall a specific autobiographical memory when behaviour relevant to the trait word was displayed. The conditions of the experiment involve a sequence of two of these tasks (e.g. describe then recall; define then recall). Klein and Loftus (1993) reasoned that if self-knowledge is used to organise episodic memories, then a prime involving thinking about a trait with reference to self (the describe task) should improve reaction time when giving a memory involving that trait (the recall task). However, their results have consistently shown that the describe task does not prime retrieval in the recall task (relative to the define task). Klein and colleagues cite this as evidence that self-knowledge and behavioural exemplars (specific trait-related memories) are functionally independent (e.g. Kihlstrom, Beer \& Klein, 2002; Klein et al., 2008). This theory is borne out by case studies who demonstrate episodic memory impairments but retain self-knowledge (e.g. Klein, Cosmides, Costabile, \& Mei, 2002; Rathbone et al., 2009; Tulving, 1993). However, Klein and colleagues (e.g. Klein, Rozendal, and Cosmides, 2002; Klein et al., 2008) also note that whilst semantic self-knowledge and episodic 


\section{SWITCH COSTS IN THE SELF-MEMORY SYSTEM}

autobiographical memories do not interact by necessity, they are likely to interact in normal circumstances.

Counter to the theoretical viewpoint of Klein and colleagues, Sakaki (2007) claimed that self-images are closely related to autobiographical memories, and showed significant priming of episodic memories using semantic self-knowledge. This task employed a paradigm in which participants were shown an 'I am...' sentence as a prime, and then asked to recall an autobiographical memory in response to a cue-word that followed. There were three conditions. In one, the prime was related to the cue-word (e.g. prime 'I am intelligent,' followed by the cue-word 'smart' to which the participant had to recall an autobiographical memory of being smart). In the next condition, the prime was unrelated to the cue-word (e.g. prime 'I am lazy,' followed by cue word 'nervous'). Third there was a control condition in which the prime was a letter-string $(x x x x)$. Results showed that mean autobiographical memory generation time was significantly faster in the related prime condition than for unrelated prime and control conditions. In direct contrast to Klein and Loftus (1993), these results suggest that accessing semantic trait representations (e.g. I am intelligent) aids the recall of personal episodes associated with that trait. Additionally, after the experiment participants were asked to score the primes used (e.g. 'I am lazy') on a scale of 1 to 5 for self-descriptiveness ( 1 being 'extremely unlike me,' 5 being 'extremely like me'). Analysis showed that when self-descriptiveness was high, participants were significantly faster at recalling memories in the related-prime condition than in the un-related prime condition (compared to when self-descriptiveness was low). Sakaki (2007) concluded that abstract representations of self-descriptive traits appeared to be linked to trait-related autobiographical memories.

This research by Sakaki (2007) suggests a self-based organisational structure, controlling the retrieval of autobiographical memories. Sakaki posited that activation of nodes for self-concept might activate nodes for associated autobiographical memories, resulting in high accessibility for autobiographical memories that are consistent with a particularly salient self-concept. Indeed, 


\section{SWITCH COSTS IN THE SELF-MEMORY SYSTEM}

structural links between self-concept and related personal episodes might be reflective of an executive cognitive mechanism through which self-concept influences autobiographical memory retrieval (Conway, 2005; Sakaki, 2007). Sakaki's research has, however, been criticised by Klein et al (2008), who suggested that the priming studies reported were flawed by their use of only a single recall target task. In addition, they argued that Sakaki's conclusions failed to acknowledge the literature, from both normal and neuropsychological populations, that suggests semantic selfknowledge can operate independently of episodic memory (e.g.; Klein \& Loftus, 1993; Klein, Loftus \& Kihlstrom, 1996; Klein, Rozendal \& Cosmides, 2002; Tulving et al., 1993).

There is, as yet, no definitive picture of the complex relationship between self processes and autobiographical retrieval. As illustrated by the studies of Klein and Sakaki, described above, different methodological approaches elicit different effects with contrasting implications. Some studies (such as Sakaki, 2007), suggest strong ties between aspects of self and associated memory sets, whereas others (e.g. Klein \& Loftus, 1993) have revealed little evidence that the two areas are related. In spite of ongoing debate in the field, there is substantial evidence to suggest that in certain cases there are close associations between self-knowledge and autobiographical memories (e.g. Conway and Bekerian, 1987; Stopa \& Jenkins, 2007; Wang, 2008). Thus, even if episodic memories are not necessarily activated during processes involving self-knowledge, there are nevertheless many examples of the two processes closely interacting.

This paper presents two studies that aimed to investigate the accessibility of autobiographical memories in relation to self-images. They were designed to examine how episodic memory accessibility might be affected when self-images were manipulated as cues in a task-switch design. In particular, we predicted that according to the executive view of the working self, there should be a switch cost involved in accessing the appropriate structure with which to cue the retrieval of memories.

\section{Study 1}




\section{SWITCH COSTS IN THE SELF-MEMORY SYSTEM}

In order to compare retrieval of autobiographical memories cued by self-images (e.g. 'I am a student') across a variety of conditions, a task-switching experimental paradigm was adopted. The basis for this approach was a drive to investigate the executive nature of self-processes in the retrieval of autobiographical memories. Task-switch designs are well-suited to this type of experimental question, as they allow examination of the relative control processes involved in switching between two different tasks (Wylie and Allport, 2000). Thus, Study 1 examined the switchcosts involved in retrieving autobiographical memories linked with different self-images.

Tasking switching studies are based on the premise that switching between two different tasks usually produces a significant slowing in performance, relative to engaging in the same task repeatedly (Jersild, 1927). For example, Spector and Biederman (1976) measured the reaction time taken by participants to add or subtract three from items in a list of single digit numbers. In the repeat condition, participants simply had to carry out one task (addition or subtraction) repeatedly, whereas in the switch condition, participants had to alternate between addition and subtraction. Participants consistently took longer to alternate between tasks in the switch condition (i.e. there was a greater 'switch cost') than in the repeat condition.

The dependent variable in task-switching studies is generally either a measurement of list completion time (Spector and Biederman, 1976) or reaction time (e.g. Rogers and Monsell, 1995; Merian, 1996). As Baddeley et al. (2001) pointed out, the advantage of measuring individual reaction times is that the experimenter can provide cues related to the task that is required, and experimentally manipulate the time between cue and stimulus presentation. If switch-costs are purely automatic in nature, then it would be expected that presentation of a cue prior to the stimulus would not have any effect on reaction time. However, Rogers and Monsell (1995) and Merian (1996), both found that presence of a cue prior to stimulus presentation limited switchcosts, provided there was sufficient time for the participant to process the cue. These findings 


\section{SWITCH COSTS IN THE SELF-MEMORY SYSTEM}

suggest there is some form of executive control taking place during task-switching (Baddeley et al., 2001).

Ultimately, the task-switch paradigm centres on one key theory: slower performance in a taskswitching condition (compared to a repeat condition) is assumed to reflect the additional cost of control processes that are involved in the switch. Study 1 was not concerned with developing taskswitching theory per se; rather, it aimed to use the robust task-switching paradigm in a unique way, in order to investigate retrieval of self-image related autobiographical memories. In neuroscientific research, it is generally presumed that autobiographical memory retrieval is controlled by key strategic processes (Werkle-Bergner et al., 2005). In order to investigate the possibility of a selfbased control system, with executive function over autobiographical retrieval (e.g. the working self), Study 1 involved a series of task-switching trials in which autobiographical memories were cued by self-images.

There were two overall aims to Study 1 . The task-switching paradigm enabled investigation of potential switch-costs when participants generated autobiographical memories in a switch task, compared to a repeat task. Thus, first it was hypothesised that participants would generate fewer memories in a two-minute trial in which they had to switch between two self-images in alternation, compared to a trial in which two self-images were used for one minute each. Second, Study 1 aimed to investigate the potential increase in cognitive costs associated with switching between two contrasting self-images compared with two similar self-images. Previous research has suggested that memories are structured hierarchically, organised by specific lifetime periods and aspects of self (e.g. Conway, 2005; Wang, 2008; Stopa \& Jenkins, 2007). Thus, it was hypothesised that participants would generate fewer memories when switching between self-images that were contrasting (never present at the same time), than they would with self-images that were very similar.

\section{Method}


Participants. Forty undergraduate and postgraduate students (30 female, 10 male; mean age 24.2, $S D=8.63$, range 19-61) participated for course credits, or volunteered.

Design. All participants generated four self-images, in the form of 'I am...' identity statements. These consisted of two self-images that were judged by the participant to be strongly contrasting (termed Contrasting Identity 1 and Contrasting Identity 2, or $\mathrm{Cl} 1$ and $\mathrm{Cl} 2$ ), and two that were deemed to be very similar, (termed Similar Identity 1 and Similar Identity 2 or SI 1 and SI2). These four identity statements were then used by the participant to cue memories across four trial conditions: two switching trials and two repeat trials, manipulated within subject. The four trials are described in more detail below. All trial conditions were fully counterbalanced using a Latin square. The order, repeated every four participants, is shown in Table 1.

(Insert Table 1 about here)

Procedure. The first part of the study consisted of a questionnaire in which participants gave their age and gender, and completed a list of 20 self-images. Participants were asked to generate stable and enduring 'I am' statements, reflecting long-term aspects of their sense of self. Next, participants were asked to choose and write down the two self-images that they felt were the most different to each other. They were reminded that the self-images they chose would be ones they would be asked to give memories about. They were advised that they should be two aspects of their sense of self that wouldn't ever be present at the same time (e.g. 'I am competitive' and 'I am caring'). They were then asked to write down the two self-images that were most similar to each other. These were suggested to be two aspects of their sense of self that were often present at the same time (e.g. 'I am a person with strong family-ties' and 'I am a sister.' Or 'I am active' and 'I am a runner'). The final part of the questionnaire required participants to write down the age they were when they felt each of the self-images became a defining part of their identity. ${ }^{i}$ Participants then used the four self-images to generate autobiographical memories (a verbal one sentence description of a specific autobiographical event) in one of four counterbalanced trial orders (as shown in Table 1). 


\section{SWITCH COSTS IN THE SELF-MEMORY SYSTEM}

For example, participants assigned to Order A spent one minute generating autobiographical memories associated with Similar Identity 1 (SI1), followed by one minute of autobiographical memory generation associated with $\mathrm{SI} 2$. They then spent two minutes switching between memories associated with $\mathrm{SI} 1$ and $\mathrm{SI} 2$, then two minutes switching between Contrasting Identity $1(\mathrm{Cl} 1)$ and $\mathrm{Cl}$ 2. Finally, they generated memories associated with $\mathrm{Cl} 1$ for one minute, and $\mathrm{Cl} 2$ for one minute. Participants were advised not to repeat any memories that might have been given before.

It was important that participants generated specific episodic autobiographical memories, rather than semantic general event memories, as this study aimed to investigate the most specific level of autobiographical memory. To ensure episodic memories were accessed, there was a practice phase before the task-switching trials, where participants were prompted to give specific events, which should have taken place for longer than a minute but less than a day, and be associated with a sense of the self in the past. Feedback was given on these memories generated in the practice phase.

\section{Results}

The results were analysed by task (repeat or switching) and self (contrasting or similar). Figure 1 shows the mean number of memories generated in two minutes across all four trial types.

(Insert Figure 1 about here)

Figure 1 shows that for both contrasting self-images and similar self-images, there were fewer memories produced in the switch trials than in the repeat trials. A $2 \times 2$ repeated measures ANOVA was carried out comparing the two levels of task (repeat; switch) with two levels of self (contrasting; similar). Results revealed a significant main effect of task: $F(1,39)=20.57, p<.001$, partial $\eta^{2}=.35$. Thus, participants produced significantly fewer autobiographical memories in switch trials than in repeat trials. However the main effect of self, and the task x self interaction, were non-significant, 


\section{SWITCH COSTS IN THE SELF-MEMORY SYSTEM}

with respective values of: $F(1,39)=2.12, p=.16$, partial $\eta^{2}=.05$, and $F(1,39)=1.21, p=.28$, partial $\eta^{2}=.03$

Against predictions, switching between contrasting self-images did not lead to a reduction in the number of memories produced, when compared to switching between similar self-images. In fact, if anything, the switch-costs were significantly higher between similar self-images compared to between contrasting self-images ( $t=2.23, d f=39, p=.032$ ), possibly suggesting some role of interference between similar self-images in the retrieval of memories, rather than the facilitation we had anticipated - though it must be noted that the interaction was not significant.

\section{Discussion}

The experimental aims of Study 1 were twofold. Firstly, we expected switch costs in retrieving memories to alternating self-image cues. Results supported this prediction, as participants produced significantly fewer memories in switch trials than repeat trials. Secondly, it was expected that participants would generate fewer memories when switching between self-images that were contrasting than between self-images that were very similar. We anticipated a greater cognitive cost in switching between different self-images than between similar ones. However, there was no apparent increase in memory generation when switching between similar self-images as opposed to contrasting self-images. In fact, the results indicated an interference effect; participants generated a significantly higher mean number of memories when switching between contrasting, compared to similar, self-images.

One explanation for these results is that the memory sets for similar self-images overlapped. In the similar self-image condition, many participants chose closely related traits such as 'I am hardworking' and 'I am a worrier.' It is possible that this overlapping led to participants running out of memories in the switch trial, as both self-images might have cued the same memories (e.g. a memory of revising for an exam). When participants were asked to switch between two contrasting 


\section{SWITCH COSTS IN THE SELF-MEMORY SYSTEM}

self-images however (such as 'I am a loyal friend' and 'I am shy') they would have had two more distinct categories to generate memories from. Therefore, it is possible that fewer memories were given when switching between similar selves because the relevant memories available were simply exhausted more quickly, leaving the participant without enough readily accessible memories to fill the two minute retrieval period. This problem was also an outcome of the design, which used only four self-images. As each of the four trials required two self-images, each statement was used twice, and memories were not permitted to be repeated. This methodological limitation was taken into account in the design of a second task-switch study, presented below.

Interestingly, in the task switching literature, there are often 'asymmetric' differences in task switch costs according to the difficulty of the task in question (for a review, see Kiesel et al., 2010). For instance, switch costs are usually higher for easier tasks (e.g. reading a colour word) than more difficult ones (e.g. naming the colour ink of a word) (Allport, Styles \& Hsieh, 1994); or switch costs are larger in a first language than in a second one (Meuter \& Allport, 1999). In the case of language processing the dominant language has higher states of activation in the cognitive system, such that it exerts more of an influence when having to switch to the second language. Whilst our self-images do not differ in terms of their accessibility in the same way that first and second languages do, it is clear that a similar identity will have a greater number of associations with a second similar one, and so, as with the inhibition of a dominant first language, there may be a greater switch cost involved in the suppression of the related self-image. By this view, following an interference account of switch costs (cf. Kiesel et al. 2010) the fact that switch costs were actually greater for similar selves suggests indeed that the costs were related to the proximities of the selves as we had predicted initially. However, whether related selves are party to the same interference and switch cost processes as Stroop-like and language switch experiments is not clear.

In summary, although there was no support for our hypothesis of greater switch costs associated with switching between contrasting compared to similar self-images, the results of Study 1 clearly 


\section{SWITCH COSTS IN THE SELF-MEMORY SYSTEM}

supported our main aim: there was a definite task-switching effect when participants switched between two self-images, compared to when generating autobiographical memories in the repeat trials.

\section{Study 2}

As described above, to avoid the potential for participants to run out of memories on the second trial for a given self-image, this study adopted the use of eight 'I am...' statements, so that each trial consisted of two new self-image cues. Further, to avoid the potential for similar statements to overlap to the point of being two descriptions of the same self-image (e.g. 'I am a worrier' and 'I am nervous'), this study was based on self-images from two different domains. As all participants were undergraduate students, we were able to choose two domains that were easy to differentiate: selfimages at university and at home. Thus, trials could be based on participants switching between similar self-images from the same domain (e.g. at university: 'I am a psychology student' and 'I am friends with Sarah'), or different self-images from different domains (e.g. at university: 'I am in the Film Society,' and at home: 'I am a daughter').

In light of the results of Study 1, we anticipated task switching costs, with participants producing fewer memories in switch trials than in repeat trials. We again were interested in whether the magnitude of the switch cost might vary according to the selves that were switched between. According to the interference account above we predicted that switching between two selves from different domains (e.g. university and home) should be easier than switching between two selves from the same domain (where switch costs should be higher).

Study 2 also included an additional semantic task. This task was identical in design to the episodic task, including a series of repeat and switching trials. The use of both semantic and episodic taskswitch trials enabled a direct comparison of the generation of semantic facts and episodic autobiographical memories. Models of autobiographical retrieval are generally assumed to be 


\section{SWITCH COSTS IN THE SELF-MEMORY SYSTEM}

hierarchical (e.g. Conway, 1996; Conway and Pleydell-Pearce, 2000), with cue words (e.g. angry) first leading to semantic associates (my high school chemistry teacher), which then lead to generic categorical memories (when people used to mess around in class), which finally result in specific memory generation (the day I dropped a test tube down the plug hole). This hierarchical model predicts that participants should be much faster at generating semantic facts than autobiographical memories, thus a further prediction for Study 2 was that a higher amount of items would be generated across all conditions in the semantic task, compared to in the episodic task.

\section{Method}

Participants. Sixteen participants (12 female, 4 male; mean age 20.56, $S D=3.65$ range 19-34) took part for course credits.

Design \& Procedure. Participants completed a list of five 'I am...' statements linked with being at home, and five statements linked with being at university. They were advised that, if possible, the home identity statements should reflect aspects of their identity that are only present at home (e.g. 'I am friends with X from school,' 'I am a daughter'), and the university statements reflect identities that are only present at university (e.g. 'I am a psychology student'). Participants were then asked to choose the four most distinctive identities from each list of five, and were reminded that they would be asked to generate memories associated with them. These eight self-images were then used to cue verbal memories across four trial conditions in the episodic task. As in Study 1, the study consisted of two switching trials and two repeat trials. All trial conditions were fully counterbalanced using a Latin square.

In the semantic task, four standardised cues were given to all participants: (1) friends' names, (2) pub names, (3) street/district names, (4) landmark names. These were given as cues for both home and university, giving eight semantic categories in all. Although the task order followed the same counterbalancing as the episodic task, the order of presentation of categories was also 


\section{SWITCH COSTS IN THE SELF-MEMORY SYSTEM}

counterbalanced to ensure that participants were not always switching between, for example, landmarks at home and landmarks at university. Half of the participants completed the episodic retrieval tasks first, and half began with the semantic retrieval tasks.

Instructions were very similar to those in episodic tasks. In the repeat trials, participants were asked to spend one minute generating as many items in a category as possible, followed by another minute of item generation for a different category. In the switching trials, participants alternated between generating items from two categories for two minutes (e.g. name of friend at home, name of pub at university, name of friend at home, etc). To minimise the possibility that fluency of items generated in episodic and semantic tasks was not simply a reflection of how much time items took to describe (for example, a detailed description of an episodic event would involve more words than the name of a pub), participants were instructed - as in Study 1 - to only generate a brief title for each episodic event (e.g. last birthday, my sister's wedding). Last, participants answered questions on the potential overlap between home and university self-images. These comprised an 11-point scale of how much the participant felt their identity at university overlapped with their identity at home (0 no overlap at all; 10 completely the same person); an 11-point scale of how strange it would be to spend time with friends from university and friends from home at the same time ( 0 very strange; 10 not at all strange); and an indication of how many friends from home the participant regularly saw whilst at university (none, 1-2, 3-4, 5 or more). We also asked participants to include their home postcode, to allow a calculation of the number of miles between home and university. Finally, participants indicated their age in years when each of their 10 'I am...' identity statements became a defining part of their identity.

\section{Results}

All 16 participants completed each of the four trial conditions in both the episodic and semantic tasks. The mean number of items generated in each trial is shown in Figure 2. 'Same domain' indicates a task in which participants generated memories from self-images that were both within 


\section{SWITCH COSTS IN THE SELF-MEMORY SYSTEM}

the same category (e.g. both from university, or both from home). 'Different domain' indicates a task where participants used self-images from two different categories (e.g. home and university).

(Insert Figure 2 about here)

Figure 2 demonstrates a clear replication of the task switching effect found in Study 1: for both semantic and episodic tasks, participants generated more items for repeat trials than switch trials.

In addition, participants generated far more items across all conditions in the semantic task than the episodic task. A 2 [task: semantic; episodic] x2 [domain: same; different] x2 [trial: repeat; switch] ANOVA showed a highly significant main effect of task $\left(F[1,15]=169.22, p<.001\right.$, partial $\left.\eta^{2}=.92\right)$, a main effect of trial $\left(F[1,15]=119.25, p<.001\right.$, partial $\left.\eta^{2}=.89\right)$, and no main effect of domain $\left(F[1,15]=.47, p=.50\right.$, partial $\left.\eta^{2}=.03\right)$. There was no three-way interaction $(F[1,15]=1.35, p=.26$, partial $\left.\eta^{2}=.08\right)$, and no significant interaction between task and domain $(F[1,15]=.08, p=.78$, partial $\eta^{2}=.01$ ). This lack of significant interaction between task and domain shows that switch costs were the same whether material was chosen from home or from university. There was a marginally significant domain $x$ trial interaction $\left(F[1,15]=4.61, p=.05\right.$, partial $\left.\eta^{2}=.24\right)$, and a significant task $x$ trial interaction $\left(F[1,15]=46.71, p<.001\right.$, partial $\left.\eta^{2}=.76\right)$. This task by trial interaction was driven by the fact that there was a greater switch cost (difference between items generated in switch compared to repeat trials) in the semantic task (Mean switch cost $=14.18$ ) compared to the episodic task (Mean switch cost $=4.07$ ). To keep the analyses in line with those reported in Study 1 and to examine more closely the relationship between trial and domain within the episodic and semantic tasks, these were analysed using two separate 2 (trial) $\times 2$ (domain) ANOVAs .

A $2 \times 2$ repeated measures ANOVA on the episodic task scores across two levels of trial (repeat and switch) and two levels of domain (same and different) revealed a significant main effect of trial: 
$F(1,15)=66.08, p<.001$, partial $\eta^{2}=.82$. There was no significant main effect of domain $(F[1,15]=$ $0.57, p=.46$, partial $\left.\eta^{2}=.04\right)$ and no significant interaction between trial and domain $(F[1,15]=$ $1.41, p=.25$, partial $\left.\eta^{2}=.09\right)$.

Within the semantic task, a $2 \times 2$ repeated measures ANOVA with 2 levels of trial (repeat and switch) and 2 levels of domain (same and different) revealed a significant effect of trial: $F(1,15)=89.80, p<$ .001 , partial $\eta^{2}=.86$. Replicating the episodic memory results, there was no significant main effect of domain $\left(F[1,15]=0.25, p=.63\right.$, partial $\left.\eta^{2}=.02\right)$ and no significant interaction between trial and domain $\left(F[1,15]=2.72, p=.12\right.$, partial $\left.\eta^{2}=.15\right)$.

Finally, we examined whether potential overlaps between home and university affected task switching results. Participants reported a mean distance of 244.02 miles between home and university ( $S D=286.69$, Range $0-800)$, a mean overlap score of $6.56(S D=1.71$, Range $3-8)$, a mean strangeness score of $3.38(S D=.87$, Range $0-7)$, and a mean number of home friends seen at university of $2.44(S D=1.26$, Range $0-4)$. In an exploratory analysis we examined whether these four overlap variables correlated with any of the switch costs analysed above. There were no significant correlations between overlap of home and university and switch costs.

\section{Discussion}

Firstly, in our episodic task we replicated Study 1, in that, in generating autobiographical memories, there were significant switch costs, both within and across home and university domains according to the self-image used to cue the memory. This pattern was found for both semantic and episodic tasks, with lower memory/fact generation in switch trials compared to repeat trials for both tasks. Further, participants were able to generate around twice as many semantic facts as autobiographical memories in each condition. This result is in keeping with Conway and Pleydell-Pearce's (2000) hierarchical model of memory, which predicts that people are able to access semantic information 


\section{SWITCH COSTS IN THE SELF-MEMORY SYSTEM}

more quickly than specific autobiographical events. By instructing participants to generate brief titles for episodic memories (such as last birthday; grandma's funeral; doing final A-level) we aimed to match the length of time taken to describe episodic and semantic items. However, number of words spoken was not recorded and thus we cannot rule out the possibility that this main effect of task simply reflected the length of time taken to describe episodic events compared to semantic facts. Future studies should measure word counts for each item to ensure that overall item frequency reflects differences in accessibility and not differences in item length.

The finding that switch costs were also present in the semantic task supports the idea that both semantic and episodic autobiographical memory is organised hierarchically (e.g. Conway, 2005; Conway \& Pleydell-Pearce, 2000), around general events (e.g. going to university) and lifetime periods (e.g. time at high school). For example, we found switch costs when people alternated between naming friends from home and university, suggesting that geographical and temporal categories are used to organise sets of semantic autobiographical facts (such as friends' names), as predicted by Conway's model of autobiographical memory (e.g. Conway, 1996; 2005; Conway \& Pleydell-Pearce, 2000). Indeed, switch costs in the semantic task were greater than the episodic task, in line with previous research showing higher switch costs in easy tasks compared to more difficult ones (e.g., Allport, Styles \& Hsieh, 1994; Meuter \& Allport, 1999; Kiesel et al., 2010).

Finally we predicted that memory generation would be lower in same domain task switch trials, compared to different domain task switch trials. As in Study 1, there was no support for the magnitude of the switch cost changing according to the psychological or geographical distance between selves.

To our knowledge, Studies 1 and 2 are the first to use a task switch paradigm to examine the selfmemory relationship. The significant cognitive costs shown to result from switching between selfimages when generating autobiographical memories supports the idea that autobiographical retrieval is an effortful and complex reconstructive process (e.g. Conway \& Pleydell-Pearce, 2000). 


\section{SWITCH COSTS IN THE SELF-MEMORY SYSTEM}

The issue with interpreting this switch cost is the extent to which it is self-based. The results of Studies 1 and 2 do not support the idea that the self necessarily plays an executive role in memory retrieval, as we could expect to see broad task switch effects whether or not memories are accessed via specific self-images. However, what these data suggest is that people are much faster at generating sets of memories associated with one self-image (such as being a sister), than if they have to switch between two self-images. Taking the example of sister, the memories cued by this self-image could relate to a wide variety of different times, locations and contexts. In spite of this, the common self-image theme meant that memories were more accessible when generating memories in repeat compared to switch trials. In these experiments we did not collect details about the content of memories, however future studies could explore the thematic grouping around temporal, geographical or life-time period themes.

\section{General Discussion}

The results of Studies 1 and 2 support theories that view episodic autobiographical retrieval as an effortful process, involving activation of the self (e.g. Conway \& Pleydell-Pearce, 2000). There were clear switch-costs associated with switching between self-image cues, and even between selfrelevant semantic categories such as names of friends at home and at university. Findings comparing switches between contrasting selves (Study 1) and self-images from different domains (Study 2) were less clear, and reflect the on-going debate within the literature concerning the question of independence of episodic memories from self-knowledge.

Whilst there is some experimental support for the idea that episodic memory and self are closely linked (e.g., Sakaki, 2007; Wang, 2008), other researchers (e.g. Kihlstrom, Beer \& Klein, 2002; Klein \& Loftus, 1993; Klein et al., 2008) have found much evidence, in healthy and neuropsychological samples, that self-knowledge is special by virtue of its independence from episodic mechanisms. It is important to note, however, that Klein and colleagues never claim that the two systems function completely independently, as whilst independence can occur, the two systems might operate most 


\section{SWITCH COSTS IN THE SELF-MEMORY SYSTEM}

effectively in conjunction (Klein et al., 2008). Thus there is a functional independence between episodic memory and semantic self-knowledge, which, as defined by Tulving (1983, p. 66; cited in Klein et al., 2008), means that "one system can operate independently of the other, though not necessarily as efficiently as it could with the support of the other intact system". Indeed, Kihlstrom, Beer and Klein (2002) suggest that episodic memories may play a particularly important role in constraining semantic self-knowledge, by providing behavioural exemplars of trait-inconsistent behaviour. Indeed, research using a modified version of the self-priming paradigm has shown that a trait-describe task primes subsequent retrieval of a trait-inconsistent episodic memory (e.g. Babey, Queller \& Klein, 1998; Klein et al., 2001), in contrast to the research that has shown no such priming effect for trait-consistent episodic memories (e.g. Klein \& Loftus, 1993). Thus there are clearly important associations between self-images and episodic memories, visible in priming tasks such as those by Klein et al. (2001) and Sakaki (2007), and in fluency tasks (e.g. Rathbone \& Moulin, 2014), as well as in the findings of the present studies.

In line with Racsmány and Conway's (2006) suggestion that the hierarchical structure of autobiographical memory is well suited to inhibitory control processes, it is likely that the cognitive costs associated with switching between selves reflect inhibition of incongruent memories in conjunction with raised accessibility of congruent memories. In a series of directed forgetting studies Barnier et al. (2007) examined the role of inhibition in autobiographical retrieval and found that inhibitory control was particularly evident when related memories competed for retrieval. The results of the present research support this account, as we found greater cognitive costs associated with switching between similar, compared to contrasting, selves in Study 1.

\section{Conclusions}

The two studies presented here take us towards a better understanding of the complex relationship between self-processes and autobiographical retrieval. Our view is that the switch costs seen according to the retrieval fluency of autobiographical memories point to the organisation of 


\section{SWITCH COSTS IN THE SELF-MEMORY SYSTEM}

autobiographical memories within dynamic mental constructions such as captured in self-images.

We are not suggesting that memories are stored in such a rigid schema, but that when the goal is to retrieve past personal experiences which are consistent with the description of any one self-image, there is a cost associated with re-specifying this self-image, or switching to another. Thus we add to the ongoing debate in the field, and suggest that in the retrieval of autobiographical memories and personal semantics there are measureable effects of the self acting as an executive structure (see also Conway and Bekerian, 1987; Stopa \& Jenkins, 2007; Wang, 2008). We propose that the self is a mental structure which is subject to dynamic patterns of excitation and interference. These studies demonstrate the cognitive cost of switching between alternating self-images; a cost we propose is caused by reactivation of the relevant self-image and suppression of other, less-relevant, aspects of the self. 


\section{References}

Allport, A., Styles, E. A., \& Hsieh, S. (1994). Shifting intentional set: Exploring the dynamic control of tasks. In C. Umilta \& M. Moscovitch (Eds.), Conscious and nonconscious information processing: Attention and performance XV (pp. 421-452). Cambridge, MA: MIT Press.

Babey, S. H., Queller, S., \& Klein, S. B. (1998). The role of expectancy violating behaviors in the representation of trait knowledge: A summary-plus-exception model of social memory. Social Cognition, 16(3), 287-339.

Baddeley, A., Chincotta, D., \& Adlam, A. (2001). Working memory and the control of action: Evidence from task switching. Journal of Experimental Psychology: General, 130(4), 641-657.

Barclay, C. R., \& Subramaniam, G. (1987). Autobiographical Memories and Self-Schemata. Applied Cognitive Psychology, 1(3), 169-182.

Barnier, A. J., Conway, M. A., Mayoh, L., Speyer, J., Avizmil, O., \& Harris, C. B. (2007). Directed forgetting of recently recalled autobiographical memories. Journal of Experimental Psychology: General, 136(2), 301-322.

Çili, S., \& Stopa, L. (2015). The retrieval of self-defining memories is associated with the activation of specific working selves. Memory, 23(2), 233-53.

Conway, M. A. (1996). Autobiographical knowledge and autobiographical memories. In D. C. Rubin (Ed.), Remembering our past: Studies in autobiographical memory (pp. 67-93). New York: Cambridge University Press.

Conway, M. A. (2005). Memory and the self. Journal of Memory and Language, 53(4), 594-628.

Conway, M. A., \& Bekerian, D. A. (1987). Organization in Autobiographical Memory. Memory and Cognition, 15, 119-132. 


\section{SWITCH COSTS IN THE SELF-MEMORY SYSTEM}

Conway, M. A., \& Pleydell-Pearce, C. W. (2000). The construction of autobiographical memories in the self-memory system. Psychological Review, 107(2), 261-288.

Greenwald, A. G. (1980). The Totalitarian Ego - Fabrication and Revision of Personal History. American Psychologist, 35(7), 603-618.

Jersild, A. T. (1927). Mental set and shift. Archives of Psychology, 89, 5-82.

Kiesel, A., Steinhauser, M., Wendt, M., Falkenstein, M., Jost, K., Philipp, A. M., \& Koch, I. (2010). Control and interference in task switching-a review. Psychological Bulletin, 136(5), 849-74.

Kihlstrom, J. F., Beer, J. S., \& Klein, S. B. (2002). Self and Identity as Memory. Handbook of Self and Identity (pp. 68-90). New York: Guilford Press.

Klein, S. B., Cosmides, L., Costabile, K. A., \& Mei, L. (2002). Is there something special about the self? A neuropsychological case study. Journal of Research in Personality, 36(5), 490-506.

Klein, S. B., Cosmides, L., Tooby, J., \& Chance, S. (2001). Priming exceptions: A test of the scope hypothesis in naturalistic trait judgments. Social Cognition, 19(4), 443-468.

Klein, S. B., \& Loftus, J. (1993). Behavioral Experience and Trait Judgments about the Self. Personality and Social Psychology Bulletin, 19(6), 740-745.

Klein, S. B., Loftus, J., \& Kihlstrom, J. F. (1996). Self-knowledge of an amnesic patient: Toward a neuropsychology of personality and social psychology. Journal of Experimental PsychologyGeneral, 125(3), 250-260.

Klein, S. B., Robertson, T. E., Gangi, C. E., \& Loftus, J. (2008). The functional independence of trait self-knowledge: Commentary on Sakaki (2007). Memory, 16(5), 556-565.

Klein, S. B., Rozendal, K., \& Cosmides, L. (2002). A social-cognitive neuroscience analysis of the self. Social Cognition, 20(2), 105-135. 


\section{SWITCH COSTS IN THE SELF-MEMORY SYSTEM}

Markus, H. (1977). Self-Schemata and Processing Information about Self. Journal of Personality and Social Psychology, 35(2), 63-78.

Markus, H., \& Kunda, Z. (1986). Stability and Malleability of the Self-Concept. Journal of Personality and Social Psychology, 51(4), 858-866.

Meiran, N. (1996). Reconfiguration of processing mode prior to task performance. Journal of Experimental Psychology: Learning, Memory and Cognition, 22, 1423-1442.

Meuter, R. F. I., \& Allport, A. (1999). Bilingual language switching in naming: Asymmetrical costs of language selection. Journal of Memory and Language, 40, 25-40.

Racsmány, M., \& Conway, M. A. (2006). Episodic inhibition. Journal of Experimental Psychology: Learning, Memory, and Cognition 32(1), 44-57.

Rathbone, C. J., \& Moulin, C. J. A. (2014). Measuring autobiographical fluency in the self-memory system. The Quarterly Journal of Experimental Psychology, 67(9), 1661-7.

Rathbone, C. J., Moulin, C. J. A., \& Conway, M. A. (2009). Autobiographical memory and amnesia: using conceptual knowledge to ground the self. Neurocase, 15(5), 405-418.

Rogers, R. D., \& Monsell, S., (1995). Cost of a predictable switch between simple cognitive tasks. Journal of Experimental Psychology, Human Perception and Performance, 124, 207-231.

Sakaki, M. (2007). Semantic self-knowledge and episodic self-knowledge: Independent or interrelated representations? Memory, 15(1), 1-16.

Spector, A., \& Biederman, I. (1976). Mental set and shift revisited. American Journal of Psychology, 89, 669-679. 


\section{SWITCH COSTS IN THE SELF-MEMORY SYSTEM}

Stopa, L., \& Jenkins, A. (2007). Images of the self in social anxiety: Effects on the retrieval of autobiographical memories. Journal of Behavior Therapy and Experimental Psychiatry, 38(4), 459-473.

Tulving, E. (1983). Elements of Episodic Memory. New York: Oxford University Press.

Tulving, E. (1993). Self-knowledge of an amnesic individual is represented abstractly. In T. K. Srull \& R. S. Wyer (Eds.), Advances in Social Cognition (Vol. 5). Hillsdale, NJ: Erlbaum.

Wang, Q. (2008). Being American, being Asian: The bicultural self and autobiographical memory in Asian Americans. Cognition, 107, 743-751.

Wang, Q., \& Ross, M. (2005). What we remember and what we tell: The effects of culture and selfpriming on memory representations and narratives. Memory, 13(6), 594-606.

Werkle-Bergner, M., Mecklinger, A., Kray, J., Meyer, P., \& Duzel, E. (2005). The control of memory retrieval: Insights from event-related potentials. Cognitive Brain Research, 24(3), 599-614.

Wylie, G., \& Allport, A. (2000). Task switching and the measurement of "switch costs". Psychological Research-Psychologische Forschung, 63(3-4), 212-233. 
SWITCH COSTS IN THE SELF-MEMORY SYSTEM

\section{Figure Captions}

Fig. 1: Mean numbers of memories generated by trial type, Study 1 (error bars show standard error)

Fig. 2: Mean numbers of episodic memories and semantic facts generated by trial type, Study 2 (error bars show standard error) 
Table 1: Counterbalanced order of trials

Trial Order

A Repeat (SI1 \& SI2), Switching (SI1 \& SI2), Switching (CI1 \& CI2), Repeat (CI1 \& Cl2)

B Repeat (CI1 \& Cl2), Switching (CI1 \& Cl2), Switching (SI1 \& SI2), Repeat (SI1 \& SI2)

C Switching (SI1 \& SI2), Repeat (SI1 \& SI2), Repeat (CI1 \& Cl2), Switching ( $\mathrm{Cl} 1$ \& $\mathrm{Cl} 2)$

D Switching ( $\mathrm{Cl} 1$ \& $\mathrm{Cl} 2)$, Repeat ( $\mathrm{Cl} 1$ \& $\mathrm{Cl} 2)$, Repeat (SI1 \& SI2), Switching (SI1 \& SI2) 


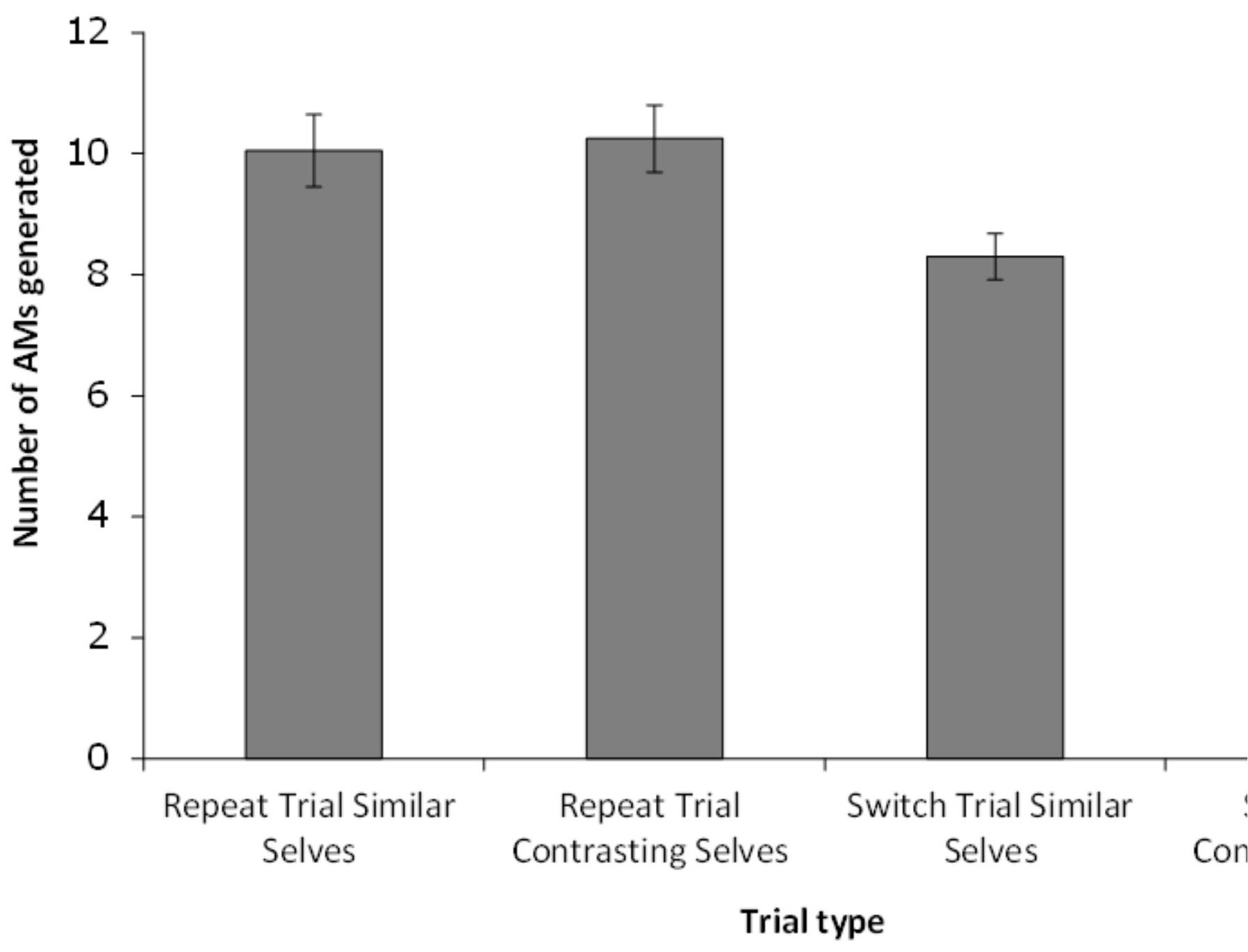




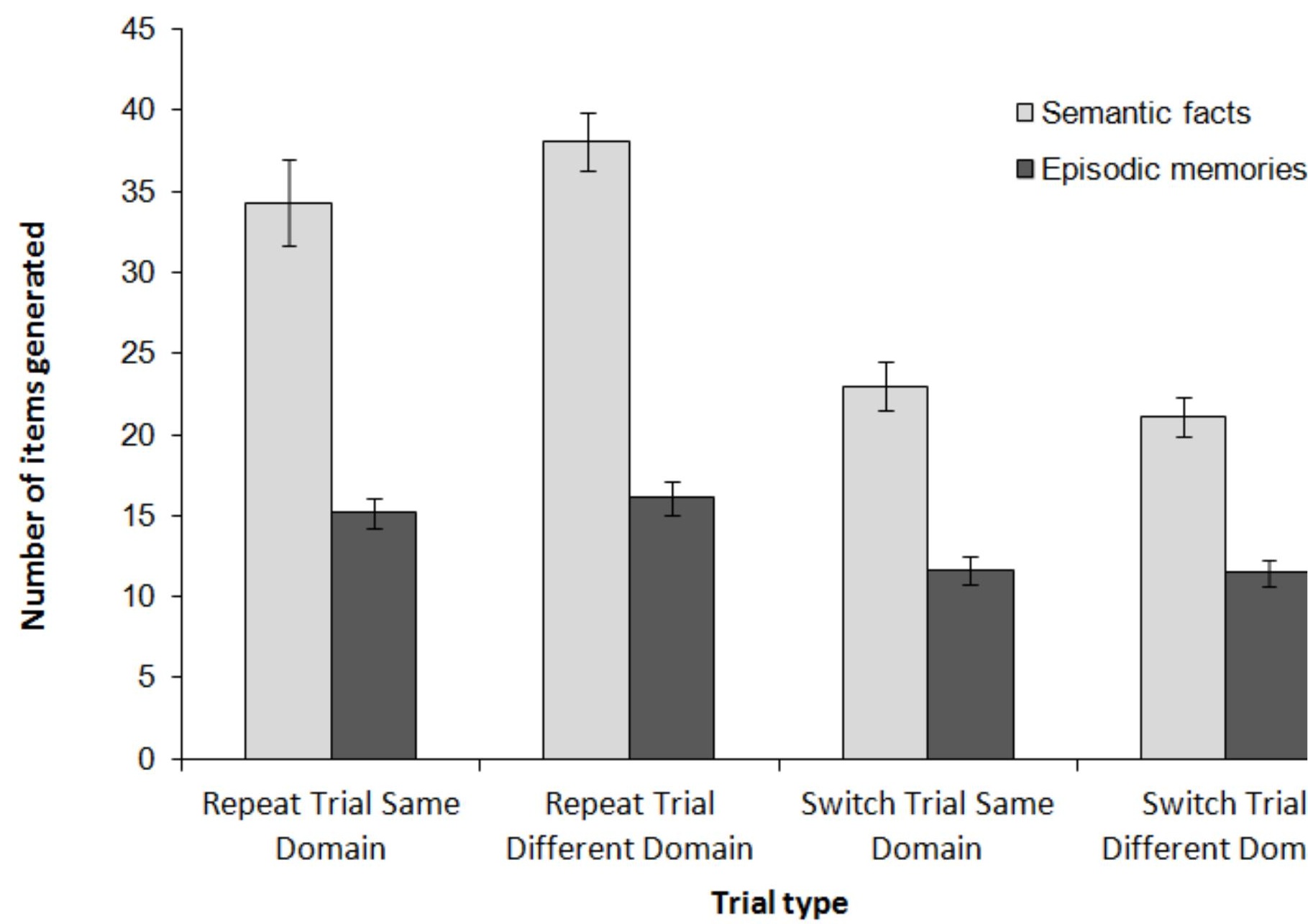

'Data relating to age of identity formation was collected for the purposes of a larger cross-study database. As these data were not relevant to the present study no analyses involving this variable are reported. 